After studying abroad, and particularly in Vienna, where he received the O.M. Degree, he returned to Boston, and became lecturer at his old medical school, where in 1888 he was made Professur of Otology, a Chair which he occupied with approbation until 1913, when, on resigning the appointment, he was made Emeritus Professor.

From 1879 until 1882 Dr. Blake edited the American Journal of Otology, in addition to which he wrote a book on "Operative Otology," together with many articles in medical and other journals on his particular branch of medicine. In the midst of these professional activities he also found time to take a prominent interest in educational and other public work.

Dr. Blake was twice married, and it will be an added sorrow to those who had met Dr. and Mrs. Blake in recent years to learn that she also has recently died.

Prof. Urban Pritchard writes:

"I was deeply grieved to hear of the death of my old friend, Dr. Clarence Blake.

"Like all of us in this country, I had very great respect for him, both on account of his valuable work in otology and for his sterling character.

"His writings are too well known to require any mention by me, but I would like to remind my colleagues of his connection with the invention of the telephone. Dr. Graham Bell comsulted him on the physiological aspects of the work, and, when the company was formed to carry out the invention, the directors offered Dr. Blake a valuable post as adviser, but he was far too keenly interested in medicine to give it up for such a post.

"I was always struck by his keenness for work, his conscientiousness, and moreover by his extreme accuracy, so that one could absolutely depend on everything he stated.

"Prof. Clarence Blake was President of the International Otological Congress in Boston, which he made a great success. He was very anxious that these Congresses should continue to flourish, and a few weeks ago I had a letter from him urging the importance of the International Otological Congress re-assembling soon after the war was over.

“ 55, Wimpole S'Treet ;

"Urban Pritcharid.

"March 7, 1919."

\title{
JAMES MaCkenzie Booth, M.D.,
}

Aberdeen.

Br the death of Dr. Mackenzie Booth, of Aberdeen, our speciality has lost a worthy representative of the older school, and the general circle of medicine in Scotland has lost a striking and charming personality.

Mackenzie Booth was an Aberdonian, having been born in the granite city in 1855. Here he received his scholastic and medical education, graduating M.A. in 1875, M.B., C.M. in 1877, and M.D. in 1888.

After spending some time in Vienna, he settled down in 1880 in his native city, being made Surreon to the Ear and Throat Department of the Aberdeen Dispensary. Thereafter he became University Lecturer on Diseases of the Ear, Nose and Throat, but drifted into general surgery as years went on, with the appointments as Surgeon and Lecturer on Clinical Surgery to the Aberdeen Infirmary.

He earned for himself a position in our speciality which secured for him the secretaryship of the Otological Section of the British Medical Association Meeting in Newcastle-on-Tyue in 1892, and until his last 
years he remained an oto-laryngologist of distinction and of practical importance.

To those of us who had experienced the animation and enthusiasm of his mind, his death brings almost the same shock of surprise as is aroused when a young colleague is lost, and that we may well regard as the most enviable characteristic of his make-up, its energy and fresh youthfulness.

D. M.

\section{NOTES AND QUERIES.}

Errata in June Number.

P. 188, last par., line 3, for made read explained.

P. 207, line 2 from bottom, for Mager read Mayer.

P. 227, under illustration for wire read was.

The Belaian Society or Otology, Rhinology, and Lakygology.

The meeting of the above Society will be held at the Hopital Sainte-Elisabeth, on July 12 and $13,1919$.

The President is Dr. Trétrôp, Avenue van Eyck, 46, Antwerp; the SecretaryGeneral, Dr. Ledoux, Rue Lebeau, 33, Brussels.

We hope that as many British representatives as possible will make an effort to attend the first meeting of our Belgian confreres since the war broke out.

\section{BOOKS RECEIVED.}

A Yision of the Possible: What the R.A.M.C. might become. By Sir James W. Barrett, C.B., C.M.G., M.D. Price $9 s$. net.

Le Français. Enseigné par la méthode intuitiye et directe. Par P. Dessagnes. Masson et Cie., Editeurs, 120, Boulevard St. Germain, Paris, 1919. Price 5 fr. net. 